\title{
Using the Elevated plus Maze Task in Assessing Anxiety and Fear in Swiss White Mice
}

\author{
Aduema $W^{1 *}$, EE Osim² and AA Nwankwo ${ }^{3}$ \\ ${ }^{1}$ Department of Human Physiology, Faculty of Basic Medical Sciences, PAMO, University of Medical Sciences, Port Harcourt, Nigeria \\ ${ }^{2}$ Department of Human Physiology, Faculty of Basic Medical Sciences, College of Medicine, University of Calabar, Calabar, Nigeria \\ ${ }^{3}$ Department of Human Physiology, Faculty of Basic Medical Sciences, College of Health Sciences, Abia State University, Uturu, Nigeria
}

Submission: January 23, 2018; Published: April 19, 2018

*Corresponding author: Dr. Wadioni Aduema, Department of Human Physiology, PAMO, University of Medical Sciences, Rivers State, Nigeria, and Postcode? Fax: +23408038046678; Tel: 23408038046678; Email: Wadioniaduema@gmail.com

\begin{abstract}
Beans, the stable diet of Nigerians contains serotonin and its precursor, 5-HTP in significant amount. It was therefore the aim of this study to find out whether long term consumption of cooked beans (Vigna unguiculata) diet has effects on some neurobehavioural parameters notably; anxiety and fear. Thirty (30) adult Swiss white mice (18-30g body weight), were used for the study. The elevated plus maze (EPM) was employed for the evaluation of anxiety and fear related behaviour. Mice in the control group $(n=10)$ were fed normal rodent chow while mice in the cooked beans $(\mathrm{n}=10)$ and serotonin precursor fed group $(\mathrm{n}=10)$ were fed cooked beans diet $(50 \% \mathrm{w} / \mathrm{w})$ and $(0.2 \mathrm{mg} / 50 \mathrm{~g} \mathrm{w} / \mathrm{w})$ serotonin precursor diet for 4 weeks. All animals were allowed free access to clean drinking water. Daily food intake, water intake and body weight change were measured. In EPM, the duration in the open arm and centre square duration was significantly higher $(\mathrm{p}<0.001$ and $\mathrm{p}<0.05$ respectively) in the test group, while the frequency of grooming and defecation was lower in the test group $(p<0.05$ and $p<0.001$ respectively). Signifying a decrease in anxiety and fear, this was also observed in their head dips. There was also a significant $(p<0.05)$ decrease in the duration of grooming in the elevated plus maze test for the cooked beans and serotonin precursor fed group when compared to the control. Thus, chronic consumption of cooked beans diet may decrease anxiety and fear related behavior.
\end{abstract}

Keywords : Cooked beans; Anxiety; Fear; 5HTP; Mice

\section{Introduction}

Common bean (Vigna unguiculata) is a dicotyledon and belongs to the pea family (Gatel, 1994). Beans are available as the dry mature seeds or the green immature seeds which are wrapped in pods (Wortmann, 2006). Both types are edible. There are many varieties of dry bean classes depending on the colour, shape and size. Some of the commonly consumed varieties are navy, black, kidney and pinto beans. Bean are used as staple food in Nigeria and globally [1], and are a superb source of protein, carbohydrates, dietary fibre, minerals, vitamins and many phenolic compounds [2]. Bean is a very nutritious food $[3,4]$, and has been reported to exhibit that beans have anticarcinogenic, anti-mutagenic [5]; anti - inflammatory, anti-diabetic, hypoglycaemic, depurative, cardio-protective and antioxidant effects [6]. Beans are rich in serotonin and its precursor 5-Hydroxytrytophan (5-HTP) [7]. They also contain saponins, tannins, glycosides and flavonoids [7]. Akey feature of serotonins is the regulation of neurobehavior such as mood, memory, learning, and sleep [8]. Evidence suggest that serotonin acting as a neurotransmitter on both neurons and muscles is able to modulate behavior in response to changing cues, to affect egg laying, pharyngeal pumping, locomotion in the roundworm Ceanorhabditis elegans (C.elegans) [9]. Since beans contain serotonin and 5-HTP and chemicals that can potentially affect behavioral patterns, it may be worthwhile to investigate whether long-term consumption of cooked beans diet can affect behavior. This is of particular interest when considering the challenges that confront human behavior and how behavioral disorders still remain a global health concern [10]. Therefore, this study explore the effect of long term consumption of cooked beans on behavior (using mouse behavioral model).

\section{Materials and Methods}

\section{Experimental animals/grouping}

Adult Swiss white mice( $\mathrm{n}=30)$ weighing between $15-30 \mathrm{~g}$ obtained from the disease -free stock of the animal house, Department of Physiology, University of Nigeria, Nsukka were 
used for this research work. The animals were randomly assigned into three groups (10/group). Each mouse in a study group was individually housed in a plastic cage with iron gauze bottom grid and a wire screen top. The animal room was adequately ventilated, and kept at room temperature and humidity of $22 \pm 3$ ${ }^{\circ} \mathrm{C}$ and $40-70 \%$ respectively with 12 hour natural light-dark cycle. The animals in the control group(1) received normal rodent feed(rodent chow) only, while the test group received mixed feed of $50 \mathrm{~g}$ of cooked beans per every $50 \mathrm{~g}$ of rodent chow making $50 \%$ of the beans diet (test group 2) and $(0.2 \mathrm{mg} / 50 \mathrm{~g})$ serotonin precursor diet(group 3) for 4 weeks. For the purpose of this work, we are comparing only three groups (i.e. control, cooked beans and the serotonin precursor group) instead of the four groups as shown in the results.

Experimental design: The Elevated Plus maze was built according to the description of Lister (1987). The maze has two open arms $(30 \times 5 \mathrm{~cm})$ and two closed arms $(30 \times 5 \times 15 \mathrm{~cm}$ high walls) radiating from a central square $(5 \times 5 \mathrm{~cm})$. The floor of the maze is made of black (or gray) Plexiglas and the walls of clear Plexiglas. The open arms contain a slight ledge ( $4 \mathrm{~mm}$ high) to prevent the mice from slipping and falling off the edge [11]. The apparatus is located in a laboratory room $(2 \times 5 \mathrm{~m})$ and lit by a $60-$ watt red lamp for background lighting. To eliminate any lingering olfactory cues, the apparatus is always cleaned between each mouse using 70\% ethyl alcohol. Each trial is recorded manually.

\section{Procedure}

Mice were carried into the test room in their home cages and were handled by the base of their tails at all times. Mice were placed in the central square of the EPM facing the open arm. Behaviors such as head dips stretch-attend postures, grooming, line crosses, and freezing and rearing were score. The trial duration is 5-minutes. After 5 minutes, mice will be removed from the maze by the base of their tails and return to their home cage (or holding cage). The number of urinations and defecations will be recorded, and then the maze will be cleaned with a solution of $70 \%$ ethyl alcohol and permitted to dry.

Behaviors to be scored include (Brown et al., 1999; McFadyen et al., 2002; Podhorna and Brown, 2002; Yan et al., 2004):

Open arm entries: frequency with which the animal entered the open arms. All four of the mouse's paws should be in the open arms to be regarded as an entry.

Closed arm entries: frequency with which the animal enters the closed arms. All four of the mouse paws should be in the closed arms to be regarded as an entry.

Open arm duration: length of time the animal spent in the open arms.

Closed arm duration: length of time the animal spent in the closed arms.

Head dipping: frequency with which the animal lowered its head over the sides of the open arms toward the floor.

Stretch attends posture: frequency with which the animal demonstrates forward elongation of the head and shoulders followed by retraction to original position.

Rearing: frequency with which the animal stands on its hind legs.

Grooming: frequency and duration of time the animal spent licking or scratching itself while stationary.

Urination: Number of puddles or streaks of urine.

Defecation: Number of faecal bole produced.

\section{Statistical analysis}

Numerical data collected were found to be normally distributed as analyzed by the Sapiro- Wilk normality test visual inspection of $\mathrm{Q}-\mathrm{Q}$ plots and histograms. Numerical data is compared using bar charts with error bars and presented as mean and standard deviations. Statistical significance was assumed at $\mathrm{P} \leq 0.05$. Data collected were expressed as Mean \pm SEM (standard error of mean), analysis of variance (ANOVA) and the Tukey's multiple comparison tests (Post hoc test) were used for detailed analysis. "P" value less than 0.05 , was considered statistically significant. Note that, * signifies $\mathrm{P}<0.05$; ** signifies $\mathrm{P}<0.01$; ${ }^{* * *}$ signifies $\mathrm{P}<0.001$ while 'ns' signifies not significant.

\section{Results}

The following paradigms were evaluated as means of behavioral changes

\section{Behaviours scored in the elevated plus maze (EPM)}

Frequency of open arm entry: The frequency of open arm entry for mice fed control, cooked beans and serotonin precursor diets was observed to be $4.20 \pm 0.63 ; 3.75 \pm 0.63$; and $5.29 \pm 0.63 / 5 \mathrm{mins}$ respectively. The frequency of open arm entry for mice fed cooked beans and serotonin precursor was not significantly different compared to the control group. (Figure 1).

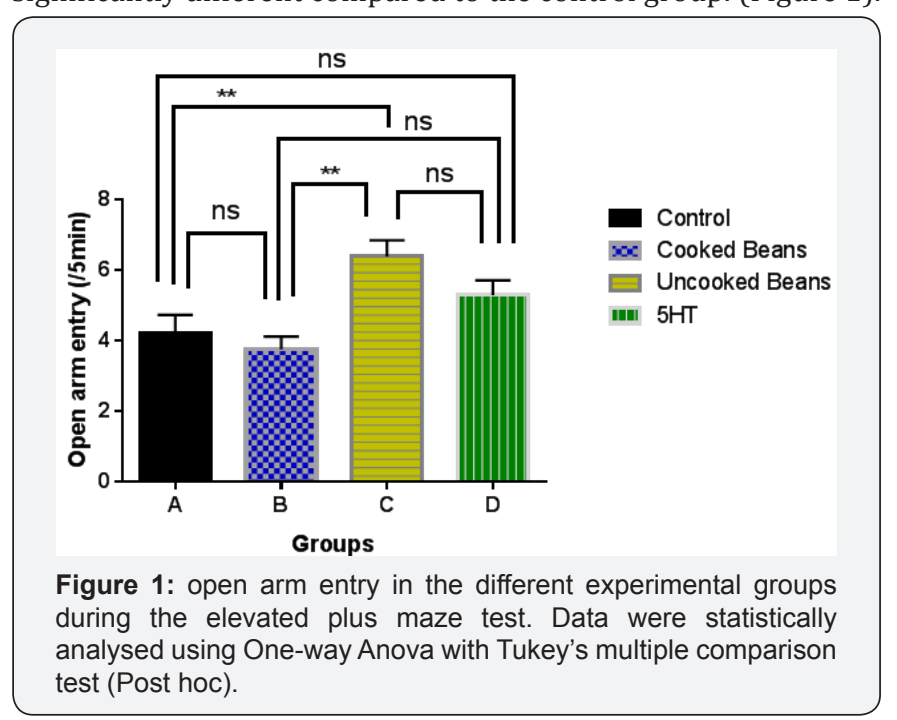


Open arm duration: The duration (time) the animals spent in the open arm of the apparatus for mice fed control, cooked beans and serotonin precursor diet was recorded as $96.62 \pm 11.13$; $186.27 \pm 5.93$ seconds and $201.26 \pm 5.40$ seconds respectively. The graph in Figure 2 shows that mice fed cooked beans and serotonin precursor was significantly higher $(\mathrm{p}<0.001)$ than that of the mice fed control diet (Figure 2).

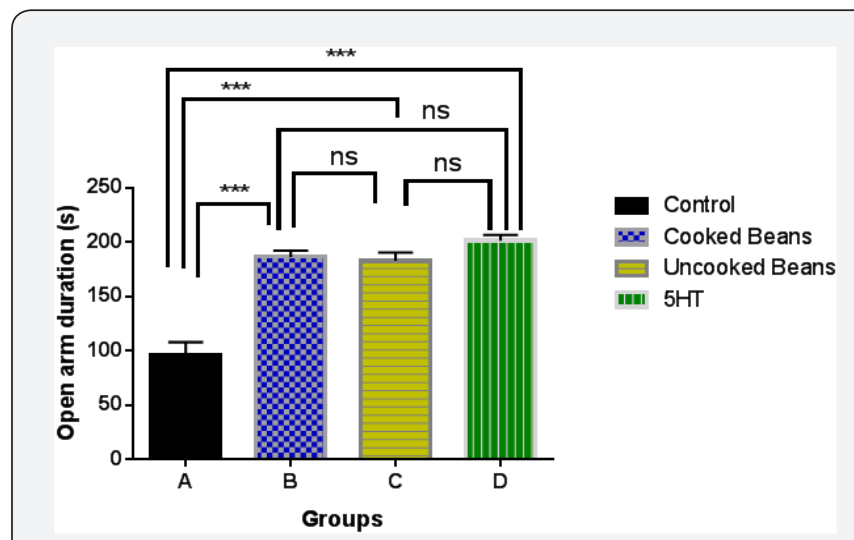

Figure 2: open arm duration in the different experimental groups during the elevated plus maze test. Data were statistically analysed using One-way Anova with Tukey's multiple comparison test (Post hoc).

\section{Frequency of Centre Square Entry}

Centre square entry following long term consumption of control, cooked beans and serotonin precursor diets were found to be $3.40 \pm 0.48 ; 2.50 \pm 0.33$; and $7.43 \pm 0.65 / 5$ mins respectively. It was observed that the frequency of centre square entry was statistically higher in the group of mice fed serotonin precursor $\operatorname{diet}(\mathrm{P}<0.001)$ compared to control. However, the frequency of centre square entry of the serotonin precursor fed mice was also significantly higher compared to the cooked beans group See Figure 3.

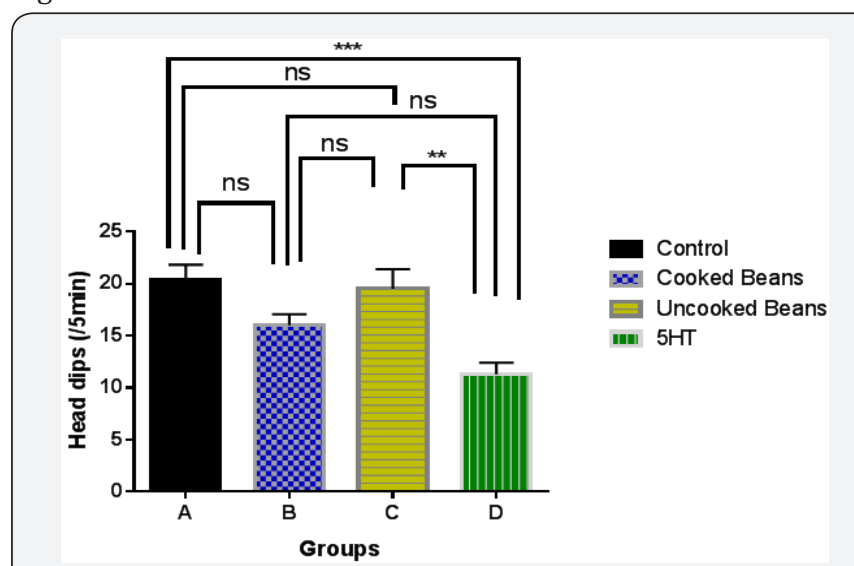

Figure 3: Head dips in the different experimental groups during the elevated plus maze test. Data were statistically analysed using One-way Anova with Tukey's multiple comparison test (Post hoc).

\section{Centre Square Duration}

Figure 4 shows the centre square duration of mice fed control, cooked beans and serotonin precursor diets was recorded as
$28.71 \pm 5.76 ; 25.35 \pm 4.61$ and $40.72 \pm 3.48$ seconds respectively. The centre square duration of the cooked beans and serotonin precursor fed mice was significantly higher $(\mathrm{P}<0.001)$ compared to control. However, the centre square duration in the group of mice fed serotonin precursor diet was significantly higher $(\mathrm{P}<0.001)$ compared to cooked beans group.

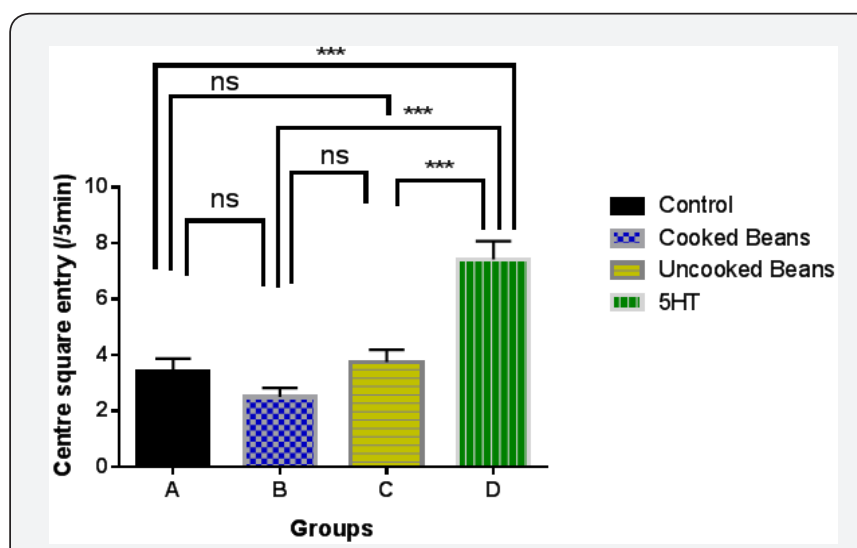

Figure 4: centre square entry in the different experimental groups during the elevated plus maze test. Data were statistically analysed using One-way Anova with Tukey's multiple comparison test (Post hoc).

\section{Frequency of Head Dipping}

The frequency with which the animal lowered its head over the sides of the open arms toward, the floor was recorded as $11.29 \pm 2.11 ; 16.00 \pm 2.08 / 5 \mathrm{mins}$ and $20.40 \pm 2.43 / 5 \mathrm{~min}$ for mice fed control, cooked, beans diet and serotonin precursor diet. Mice fed cooked beans and serotonin precursor diet showed, a higher frequency of head dips compared to control $(\mathrm{p}<0.05$; $\mathrm{P}<0.01$ ) (Figure 5).

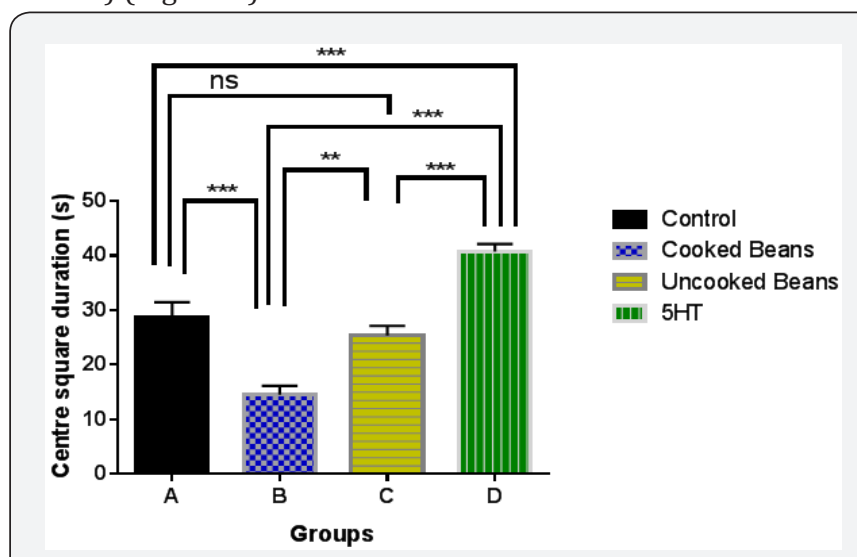

Figure 5: centre square duration in the different experimental groups during the elevated plus maze test. Data were statistically analysed using One-way Anova with Tukey's multiple comparison test (Post hoc).

\section{Grooming Frequency}

Figure 6 shows the frequency of grooming of mice fed control, cooked beans and serotonin precursor diets were recorded as $4.20 \pm 0.90 ; 2.63 \pm 0.86$ and $2.86 \pm 0.40 / 5$ mins respectively. There was significant difference among the groups. 


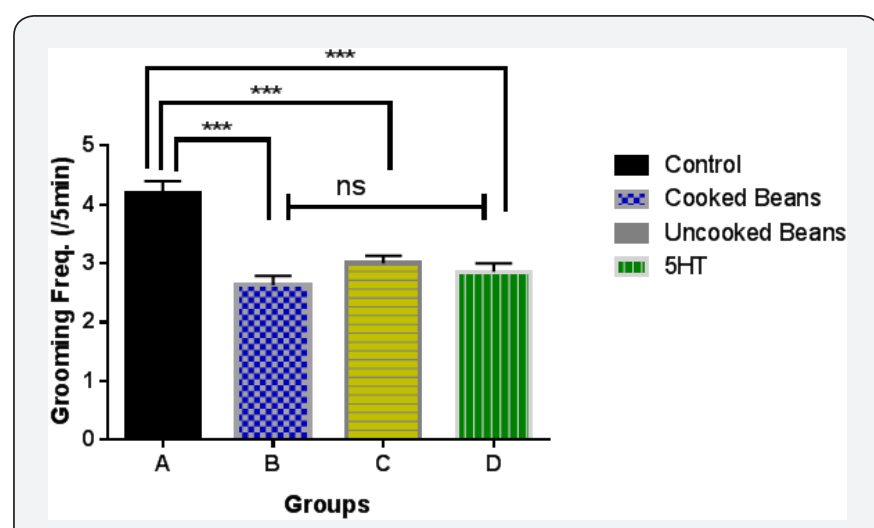

Figure 6: centre square duration in the different experimental groups during the elevated plus maze test. Data were statistically analysed using One-way Anova with Tukey's multiple comparison test (Post hoc).

Grooming Duration

The grooming duration shown in Figure 7 were, 19.44 \pm 3.25 ; $13.76 \pm 2.34$ and $10.20 \pm 0.97$ seconds for mice fed control, cooked beans and serotonin precursor diets respectively. The grooming duration of the cooked beans was significantly lower from control at $\mathrm{p}<0.001$. However, that of the serotonin precursor fed mice was significantly lower $(\mathrm{p}<0.001)$ compared to control.

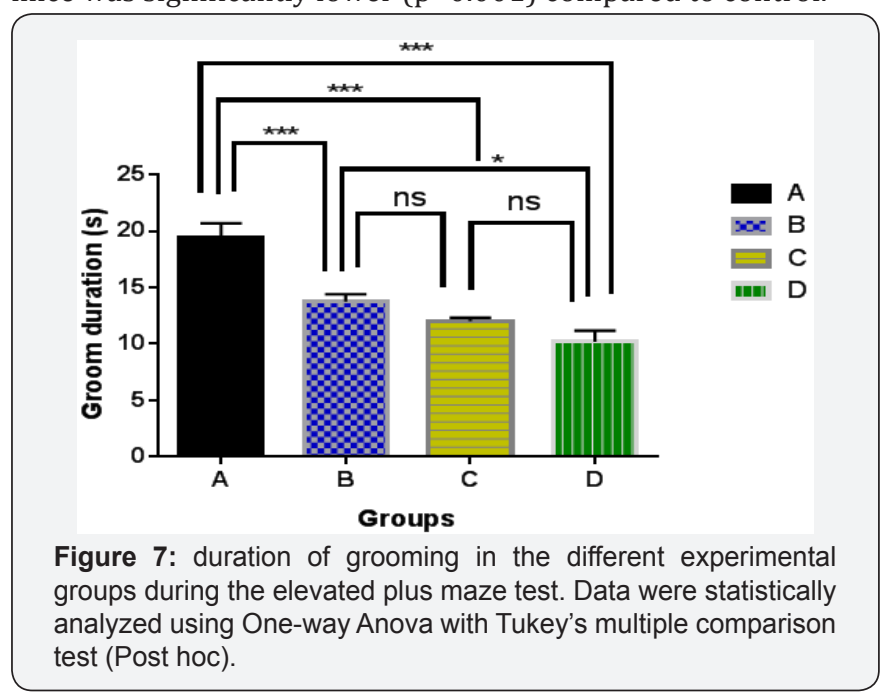

\section{Frequency of Rearing}

The frequency of rearing for mice fed control, cooked beans and serotonin precursor diets were, $20.20 \pm 1.97 ; 17.38 \pm 2.15$ and $10.14 \pm 0.70 / 5$ mins respectively. It was observed that the frequency of rearing was not significantly different in the group of mice fed cooked beans compared to control. However, the rearing frequency in the group of mice fed serotonin precursor diet was significantly lower $(\mathrm{P}<0.001)$ compared to control and at $\mathrm{p}<0.01$ compared to cooked beans fed mice. See Figure 8 .

\section{Frequency of Defecation}

Figure 9 compares the frequency of defecation in the group of mice fed control, cooked beans and serotonin precursor diets. The values are: $1.40 \pm 0.52 ; 0.25 \pm 0.16$ and $0.71 \pm 0.29 / 5 \mathrm{mins}$ respectively. The frequency of defecation in the group of mice fed cooked beans and serotonin precursor was significantly lower $(\mathrm{P}<0.001)$ compared to control.

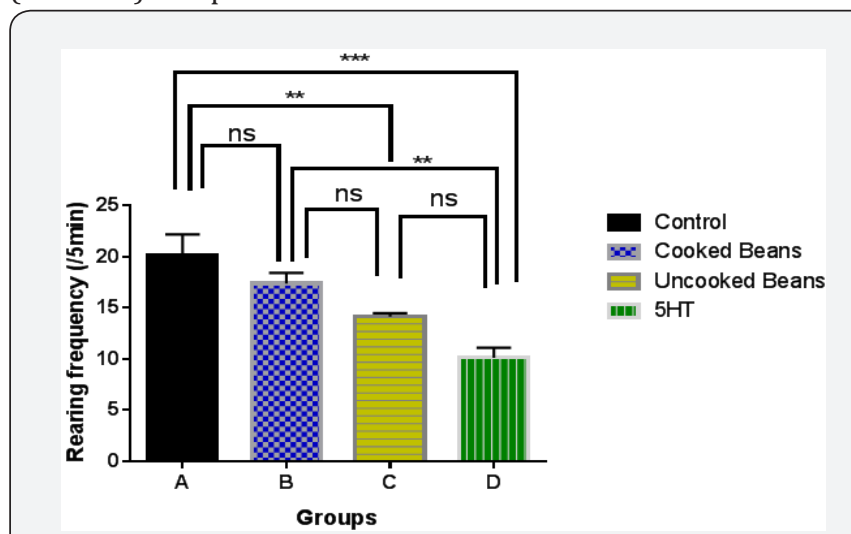

Figure 8: rearing frequency in the different experimental groups during the elevated plus maze test. Data were statistically analysed using One-way Anova with Tukey's multiple comparison test (Post hoc).

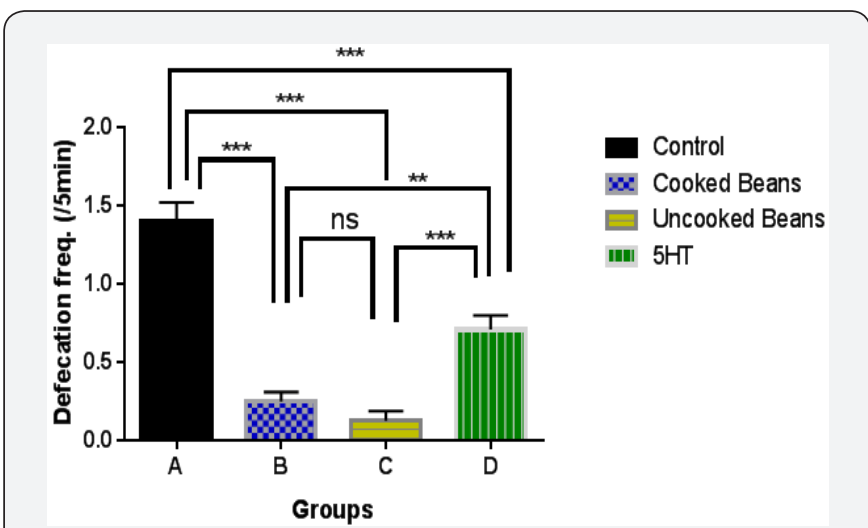

Figure 9: Defecation frequency in the different experimental groups during the elevated plus maze test. Data were statistically analysed using One-way Anova with Tukey's multiple comparison test (Post hoc).

\section{Discussion}

The elevated plus maze (EPM) consists of two 'open' arms and two 'closed 'arms' in the shape of a plus. The open arms are aversive to mice because they are open and the maze is elevated [12]. The closed arms provide a sense of safety because they are enclosed like most tests of anxiety (the light/dark box and open field). This task exploits the conflict between the natural tendency of mice to explore novel areas and fear of open spaces.

Behaviors such as open arm activity and head dipping are considered exploratory and a greater frequency of these measures shows a greater level of exploration. Fear behaviours include, closed arm activity, stretch attend posture, grooming frequency and duration, defecation and urination, a greater number of these measures implies a greater level of emotionality or fear [12]. Risk assessment behaviours such as head dips and stretch attend postures are indexes of levels of anxiety. The demonstration of anxiety in this study was done using the elevated plus maze. In the elevated plus maze, the duration of grooming was observed to be lower in the cooked beans and serotonin precursor diet fed mice. Grooming is a displacement response and it is associated 
with anxiety in rodents when they are introduced into a novel environment [13]. Another behavior that strongly correlates with anxiety is the closed arm duration in the elevated plus maze. This duration was found to be significantly lower in the cooked beans diet fed mice compared to control. Fearful mice would normally spend more time in the closed arms of the elevated plus maze. This also shows that the cooked beans and serotonin precursor diet fed mice showed decreased fear and anxiety compared to control. The frequency of defecation which is a measure of fear and anxiety was significantly lower than the control values. On the other hand, the frequency of head dips for the cooked beans and serotonin precursor fed mice was significantly higher compared to the control. The open arms duration was also significantly higher than the control values. These show a lower index level of anxiety and fear. Open arms duration and the frequency of head dips are both behavior which point to decreased anxiety. These behavior correlate strongly, and the higher their value, the less the anxiety level. So, cooked beans consumption may be reducing anxiety in the animals. On the other hand, open arm avoidance by rodents in the elevated plus maze gives a measure of anxiety [11].

Fear and anxiety are basically controlled by neural circuitry involving the amygdala mostly and the hypothalamus. Other areas of the brain that may be involved in the control of fear and anxiety are the nuclei of the hypothalamus. Electrical stimulation of the amygdala for instance is associated with fear and feeling of terror in the animals [14]. Beans is known to contain cardiac glycosides and the neurotransmitter, serotonin, etc. Cardiac glycosides reduce heart contraction [15], whereas serotonin decreases tension, lessens depressive feelings and promotes the relaxation of skeletal muscle tone [7]. Thus, it is possible that the presence of these compounds and other constituents in the beans could be responsible for the anxiolytic property of bean which act by inhibiting the excitability of the amygdala by increase in the threshold of response of the cells of these nuclei, thereby reducing fear related behaviour in the mice $[13,16]$.

These observations can also be explained by the assertion of [17] that increase level of brain serotonin facilitates the calming, relaxing and mellowing serotonin neural circuits which frequently serve to counterbalance the arousing activating dopamine/noradrenaline circuit, so that anxious, agitated emotion occurs when a person's dopamine/noradrenaline activity arousal circuits are functioning strongly, without the calming, relaxing, mellowing serotonin circuits functioning strongly as a compensatory counterbalance. It is possible that those mice did not show anxiety and fear related behaviour because beans may have increased the level of brain serotonin and thus facilitated the calming, relaxing and mellowing serotonin circuits [18-27].

In conclusion, if the result of these findings is extrapolated to man, then, long term consumption of cooked beans can be used to ameliorate panic disorders and posttraumatic stress disorders.

\section{Acknowledgement}

We acknowledged Mr. and Mrs. B.A. Aduema, Dr. Iwasam Joshua, Dr. Nmaju, and Associate Prof. A. A. Nwankwo for their priceless support.

\section{References}

1. Weder JK, Telek L, Vozári-Hampe M, Saini HS (1997) Antinutritional factors in Anasazi and other pinto beans (Phaseolus vulgaris). Plant Foods Hum Nutr 51(2): 85-98.

2. Adeyele EJ (1995) Studies of Chemical Composition and functional properties of African Yambeans (Spensotylis stenoorpa) flour. Federal University of Technology, Akure, Ondo State, Nigeria.

3. Shansudden AM, Elsayed A, Ullah A (1998) Suppression of large intestinal Cancer in F344 rats by Inositol Hexaphosphate. Carcinogenesis 9(4): 577-580.

4. Vander Poel AFB, Mollee PW, Huisman J, Liner IE (1990) Variations among species of animals in response to the feeding of heat-processed beans. Bean processing and effects on growth, digestibility and organ weights in piglets. Livestock Production Science 25(1-2): 121-135.

5. Gref E, Eaton JW (1993) Suppression of Caloric Cancer by Dietary Phytic Acid. Nutr Cancer 19(1): 11-19.

6. Bennick, E., Maurice, O. and Elizabeth R. (2008) Beans \& Health: A comprehensive Review. Frazee, MN.

7. Portas CM, Bjorvatn B, Ursin R (2000) Progress in Neurobiology. 60(1): $13-35$.

8. Brunton LB, Lazio JS, Parker KL (2005) Therapeutics. The Pharmacological Basis of Therapeutics (607-629). McGraw-Hill, New York, USA.

9. Daniel LC, Michael RK (2007) Biogenic amine neurotransmitters in C.elegans. Wormbook (pp.1-15). Worm Book, Panadesa.

10. Messman T (2005) Psychiatric drugs: Chemical warfare on humans: Interview with Robert Whitaker.

11. Trullas, R. and Skolnick, P (1993). Differences in fear motivated behaviours among inbred mouse strains. Psychopharmacology, 111: 323-331.

12. Lister, R. G (1990).Ethologically-based animal models of anxiety disorders. Pharmacological Theory, 46: 321-340.

13. Costal, B., James, B. J., Kelly, M. E., Naylor, R. J. and Tom Kins, D. M (1989). Exploration of Mice in a black and white test box: Klidation as a model of anxiety. Pharmacology, Biochemistry and Behavior, 32:777 - 785.

14. Osim, E.E (2008).Neurophysiology (pp.24-27).Calabar.University of Calabar Press.

15. Pierce, C. H (1996). Effect of chronic consumption of cardiac glycoside in food, water and sodium chloride, body composition and plasma hormones of spraugue-dawley rats.Behaviour, 59 (1). 82 - 92.

16. Adolphs, R., Gasselin F., Buchanan, T.W., Tranel, D., Scgyns, P. and Damasio, A.R (2005).A Mechanism for impaired fear recognition after amygdala damage. Nature, 433, 68 - 72 .

17. Young, S.N. andTeff, K.L (1989).Tryptophan availability, 5-HTP synthesis and 5-HT function. Progress in Neuropsychopharmacology and Biological Psychiatry, 13,373-379.

18. Andreatini, R. and Bacellar, L.F.S (2000). Animal models: trait or state measure? The test-retest reliability of the elevated plus-maze and behavioural despair. Progress in Neuro-Psychopharmacology \& Biological Psychiatry, 24: 549-560.

19. Barlow, J (2002).Antenatal anxiety, parenting and behavioural/ emotional problem in children. British Journal of Psychiatry, 181:440-1 
20. Bissong, J and Andrew (2007).Psychological treatment of post traumatic disorder.Cochrame Data Base System Review, 18(3)388.

21. Blanchard, D.C., Gabriel, G. and Blanchard, E.J (2001).Mouse defensive behaviours: pharmacological and behavioural assays for anxiety and panic. Neuroscience and Behavioural Reviews, 25,205-218.

22. Cacciopo, J.T and Gardener, W.L (1999).Emotion. Annual Review of Psychology, 50(1), 191-214.

23. D’Erana, K.S. and Francis (2004).Cognition behavioural psychotherapy: Anxiety Disorders in Children and Adolescent (pp.305-308).New York: Guildford Press.
24. Ganong, W.F., Barrette, K.E., Berman, S.M., Boitano, S. and Brooks, H.I (2010).Ganong's Review on Medical Physiology (pp.76-230).New Delhi: McGraw-Hill.

25. Nilson R (1998) A qualitative and quantitative risk assessment of snuff dipping. Regulatory Toxicology and Pharmacology 28(1): 1-16.

26. Osim EE (2012) Our consumables and our emotions. Faculty of Basic Medical Science, University of Calabar, lecture series.

27. Pini S, Maser JD, Dell'Osso L, Abelli M, Muti M (2006) Social anxiety disorder co-morbidity in patients with bipolar disorder: A clinical replication. J Anxiety Disord 20(8): 1148-1157.

\section{Your next submission with Juniper Publishers} will reach you the below assets

- Quality Editorial service

- Swift Peer Review

- Reprints availability

- E-prints Service

- Manuscript Podcast for convenient understanding

- Global attainment for your research

- Manuscript accessibility in different formats

(Pdf, E-pub, Full Text, Audio)

- Unceasing customer service

Track the below URL for one-step submission https://juniperpublishers.com/online-submission.php 